\title{
Lack of Temperature Control in Infants with Abnormalities of Central Nervous System
}

\author{
K. W. CROSS, E. N. HEY, D. L. KENNAIRD, SHEILA R. LEWIS, and H. URICH \\ From the London Hospital Medical College, London
}

\begin{abstract}
Cross, K. W., Hey, E. N., Kennaird, D. L., Lewis, S. R., and Urich, H. (1971). Archives of Disease in Childhood, 46, 437. Lack of temperature control in infants with abnormalities of central nervous system. The temperature control of 11 infants with severe abnormalities of the central nervous system has been investigated. 4 were normothermic and 7 poikilothermic. Necropsy of the latter showed that either the hypothalamus was absent or disorganized, or the long tracts through the brainstem were unidentifiable, or in one case interrupted by a cervical myelocele. The lateral horn cells, sympathetic nervous system, and brown fat appeared normal.

Where the normal reflex responses to warm and cool stimuli were absent, direct stimulation of the effector organs was attempted. Noradrenaline both stimulated heat production and constricted the peripheral skin vessels. Surprisingly, local application of pilocarpine or acetyl choline failed to stimulate the sweat glands which appeared normal at necropsy.
\end{abstract}

Temperature control is a complex mechanism depending on the integrity of the nervous system and its full co-ordination. Much of our knowledge of temperature control is derived from animal experiments. Occasionally loss of temperature control occurs in man as a result of neurological disorders (Davison and Friedman, 1937; Cooper, 1965) and this has allowed some of the underlying mechanisms to be studied.

Congenital malformation of the central nervous system may also be associated with defective temperature control. Cross et al. (1966) described the lack of temperature control in an anencephalic infant, and Gubbay (1967) in obstructive hydrocephalus.

We report here observations on temperature control in 11 infants with abnormalities of their central nervous systems. The plan of the investigation has been to test the effect of an adequate stimulus (heat or cold) on the effector organs. Where an effect was lacking we have sought to stimulate the effector organ directly with the appropriate chemical agents. Finally, where reflex effects were absent, it was only possible approximately to localize the defect in the reflex arc by necropsy. Parental permission was obtained for all

Received 8 March 1971. investigation either by the clinical staff or the investigators.

\section{Methods}

Oxygen consumption, heat storage, evaporative water loss, skin temperature, and heat flow through the skin were measured using the methods developed and described by Hill and Rahimtulla (1965), Hey (1969), and Hey and Katz (1969, 1970). Oxygen consumption was measured with the closed circuit equipment during infusions of saline and noradrenaline in saline. Saline was infused at a rate of 0.5 to $1.5 \mathrm{ml} / \mathrm{min}$ into the saphenous or umbilical vein from a motor driven syringe. L-noradrenaline was made up in a proprietary medium ('Levophed' Bayer Products Ltd.) being added when required to give a dose of 0.4 or $0.8 \mu \mathrm{g} / \mathrm{kg} \mathrm{min}$. The indirect heating test of Lewis and Pickering (1931), as modified by Young (1962) to study infants, was undertaken on 5 of these infants. A thermal sweat response was tested using starch paper previously impregnated with vapourized iodine and also with Quinizarin powder (Guttmann, 1940). Pilocarpine iontophoresis (Gibson and Cooke, 1959) was also studied on the forearm or thigh in some of these infants.

\section{Results}

For clarity the results will be set out in two main groups, depending on the presence or absence of normal temperature control. 
Group I: Normothermic infants with normal hypothalamus and connexions. Four infants will be described in this group: 3 of these infants had hydrocephalus and the fourth an occipital meningoencephalocele. Infants 1 and 4 have died. Infants 2 and 3 are living, after the insertion of a valve, but are mentally retarded. All 4 were female.

Infants 1 and 2 were sibs with hydrocephalus. Infant 1 was born at 32 weeks' gestation weighing $1.2 \mathrm{~kg}$ and developed signs of hydrocephalus at 4 weeks of age. A Spitz-Holter valve was inserted at the age of 7 weeks but she subsequently developed staphlococcal septicaemia and died. Her sib (Infant 2) was born at 36 weeks' gestation weighing $1.5 \mathrm{~kg}$, and began to develop signs of hydrocephalus at 2 weeks of age. After the insertion of a valve she is progressing but is moderately retarded.

Infant 3 was born 18 days after the expected date of delivery weighing $2.9 \mathrm{~kg}$. and developed signs of hydrocephalus at 1 week of age. After insertion of a valve she made satisfactory progress but was subsequently found to be grossly mentally retarded.

Infant 4 was born at term weighing $2.5 \mathrm{~kg}$ with an occipital meningoencephalocele. She died aged 31 days.

Investigations. Resting oxygen consumption in a neutral thermal environment was normal in all 4 babies, as was the increase in oxygen consumption when the environmental temperature was lowered to $29{ }^{\circ} \mathrm{C}$ for $20-30$ minutes. When motionless and apparently asleep after sedation (chloral hydrate, $60-80 \mathrm{mg} / \mathrm{kg}$ ) this increase in heat production was reduced, but was significantly raised as compared with the value obtained in a thermoneutral environment.

All 4 infants sweated normally to thermal stimuli at the time of investigation, and 3 infants who were studied showed the normal changes in thermal circulation index in response to variation in environmental temperature.

\section{Summary of postmortem findings.}

Case 1. Internal hydrocephalus of lateral ventricles -with complications arising from sepsis following ventriculo-jugular drainage. Cerebral tissue reduced to $0 \cdot 5-1 \mathrm{~cm}$ in thickness. Other brain structures normal.

Case 4. Asymmetrical herniation of occipital lobes into encephalocele. Diencephalic structures, including hypothalamus, in cranial cavity and normal in structure, apart from partial fusion in midline. Brainstem elongated and kinked, with main nuclear masses and fibre tracts identifiable, situated wholly within cranial cavity. Cerebellum hypoplastic and extensively scarred, partially herniated into encephalocele.

Group II: Poikilothermic infants with absent hypothalamus, or hypothalamus present but with defective or absent connexions with lateral horn cells. Seven infants will be described in this group, 2 of which were suffering from anencephaly and the remaining 5 from occipital encephaloceles or cervical myelocele. All these infants appeared to possess no thermoregulatory ability and all were found to be hypothermic while in hospital.

Two term female anencephalic infants were studied (Cases 10 and 11). One $3 \mathrm{~kg}$ infant was studied when 48 hours old and the second, a $2 \mathrm{~kg}$ infant was studied on three separate occasions when between 6 and 60 hours old. Their condition was satisfactory at the time of investigation though both infants were hypothermic on arrival in hospital. There were no signs of respiratory distress or central cyanosis.

Four mature female infants with large occipital encephaloceles (Cases 5-8) and one mature male infant with a cervical meningomyelocele were studied (Case 9).

Investigations. Resting oxygen consumption in a neutral thermal environment was low in all these infants while they were hypothermic but increased progressively as the rectal temperature rose in a warm environment towards a normal level. The rate of a chemical reaction rises exponentially with increasing temperature, the relation being described by the ratio of rates after a $10^{\circ} \mathrm{C}$ change in temperature $\left(Q_{10}\right)$ (Table I). In infant 5 an exponential relation of this type was observed on

TABLE I

\section{$Q_{10}$ Obtained on 6 Infants During Rewarming}

\begin{tabular}{c|c|c|c|c|c}
\hline Diagnosis & $\begin{array}{c}\text { Case } \\
\text { No. }\end{array}$ & $\mathbf{Q}_{10}$ & $\mathbf{r}$ & $\mathbf{n}$ & $\mathrm{T}_{\mathbf{R}}$ \\
\hline Anencephalic & 10 & $2 \cdot 54 \pm 0 \cdot 24$ & 0.97 & $\mathbf{8}$ & $33-37$ \\
& 11 & $1 \cdot 79 \pm 0.93$ & 0.93 & 7 & $31-37$ \\
Encephalocele & 5 & $2 \cdot 13 \pm 0 \cdot 12$ & 0.98 & 10 & $34-38$ \\
& & $2 \cdot 06 \pm 0 \cdot 19$ & 0.95 & 9 & $35-38$ \\
& & $2 \cdot 05 \pm 0 \cdot 18$ & 0.95 & 8 & $35-37$ \\
& 6 & $1 \cdot 55 \pm 0.11$ & 0.79 & 26 & $33-38$ \\
& 7 & $2 \cdot 14 \pm 0.14$ & 0.98 & 5 & $31-38$ \\
& 8 & $2 \cdot 05 \pm 0.33$ & 0.98 & 60 & $34-38$ \\
\hline
\end{tabular}

Note: Values for $\mathrm{Q}_{10}$ with the estimated error of the mean and correlation ratio $(r)$ for 6 infants with congenital defects of the brain studied in a neutral thermal environment, together with the number of observations on which the estimates are based (n) and the range of rectal temperature studied $\left(T_{R}\right)$ in ${ }^{\circ} \mathrm{C}$. Infant 5 with an encephalocele was studied on three occasions in the first 9 weeks of life. 


\section{Lack of Temperature Control in Infants with Abnormalities of Central Nervous System}

3 separate occasions (Fig. 1); the temperature coefficient was similar in each case but absolute values of oxygen consumption were different.

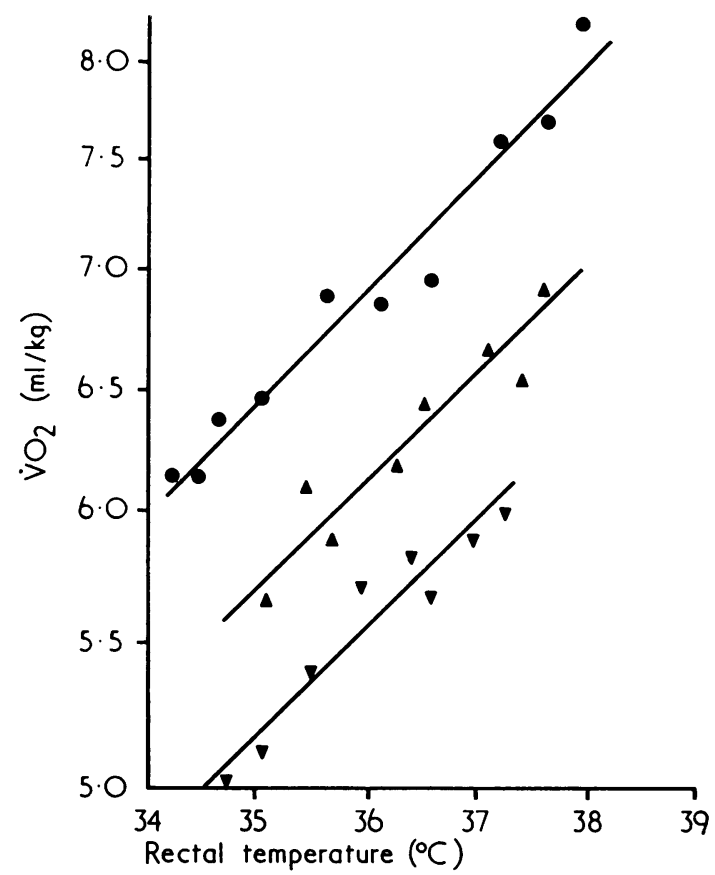

FIG. 1.-Oxygen consumption plotted against rectal temperature of infant No. 5 when the infant was being warmed after being found hypothermic in the ward on three different occasions. observations made at 34 hours of age (possibly during fitting activity); $\Delta$ observations at 60 days of age; $\nabla$ obserzations at 24 days of age while mildly sedated with chloral. The lines are the lines of best fit of $\dot{\mathrm{V} O} \mathrm{O}_{2}$ upon rectal temperature (see Table II).

No increase in oxygen consumption occurred when body temperature was normal and environmental temperature was lowered to $28-29^{\circ} \mathrm{C}$ for a period of $20-40$ minutes. The absence of any increase in heat production could have been due to a block in any part of the reflex arc. Responses to skin stimuli were present, so it seemed reasonable to suppose that the afferent side of the reflex arc was functioning, though it was impossible to test this practically. To $c$ nfirm that the defect in temperature control resulted from a lesion in the nervous system it was necessary to show that the effector organ was normal and capable of responding to direct stimulation. We therefore tested the ability of three babies to increase their heat production by infusing noradrenaline at a rate of $0.8 \mu \mathrm{g} /$ $\mathrm{kg}$ min for 15 to 30 minutes. In infant 5, a catheter was inserted into the umbilical vein but no increase in oxygen consumption was observed after intravenous noradrenaline infusion. Subsequent $x$-ray angiography showed that the catheter tip had passed into the portal system and along the splenic vein. Therefore in infants 6 and 7, it was decided to insert the catheter through the saphenous vein so that its tip lay in the inferior vena cava. A $50 \%$ increase in oxygen consumption was observed in infant 6 (Fig. 2) and a significant increase was also seen in infant 7.

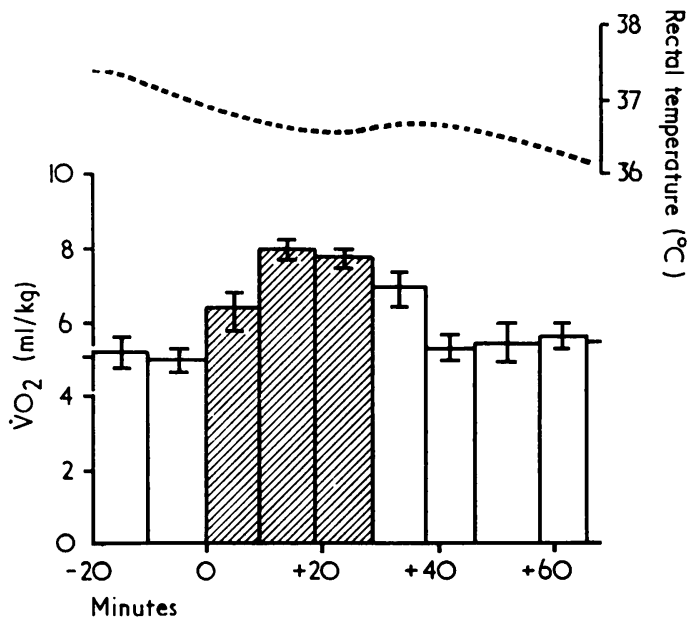

FIG. 2.-The oxygen consumption and rectal temperature of infant No. 6 before, during and after infusion of noradrenaline at $0.8 \mu \mathrm{g} / \mathrm{kg} \mathrm{min}$ (indicated by hatching). The mean oxygen consumption together with the standard deviation of the observation is shown for approximately 10-minute periods. Note that the fall of rectal temperature is halted during the infusion.

Noradrenaline infusion $(1.6 \mu \mathrm{g} / \mathrm{kg} \min$ for 25 minutes) also caused the serum glycerol to rise from 222 to $339 \mu \mathrm{M} / 1$., the non-esterified fatty acids to rise from 300 to $600 \mu \mathrm{M} / 1$., and the serum glucose to rise from 63 to $148 \mu \mathrm{g} / 100 \mathrm{ml}$ in infant 7 . Exposure to a cool environment $\left(31^{\circ} \mathrm{C}\right.$ for 2 hours while naked) on the other hand caused no change in serum glucose, but resulted in the rectal temperature falling to $35^{\circ} \mathrm{C}$ while the serum glycerol fell to $92 \mu \mathrm{M} / 1$. and the fatty acids fell to $180 \mu \mathrm{M} / 1$. (Dr. C. N. Hales, Department of Biochemistry, Cambridge).

Vasomotor responses to changes in environmental temperature were also studied in 5 infants. The indirect heating test of Lewis and Pickering (1931) was negative and no change in the thermal circulation index could be detected and no peripheral 


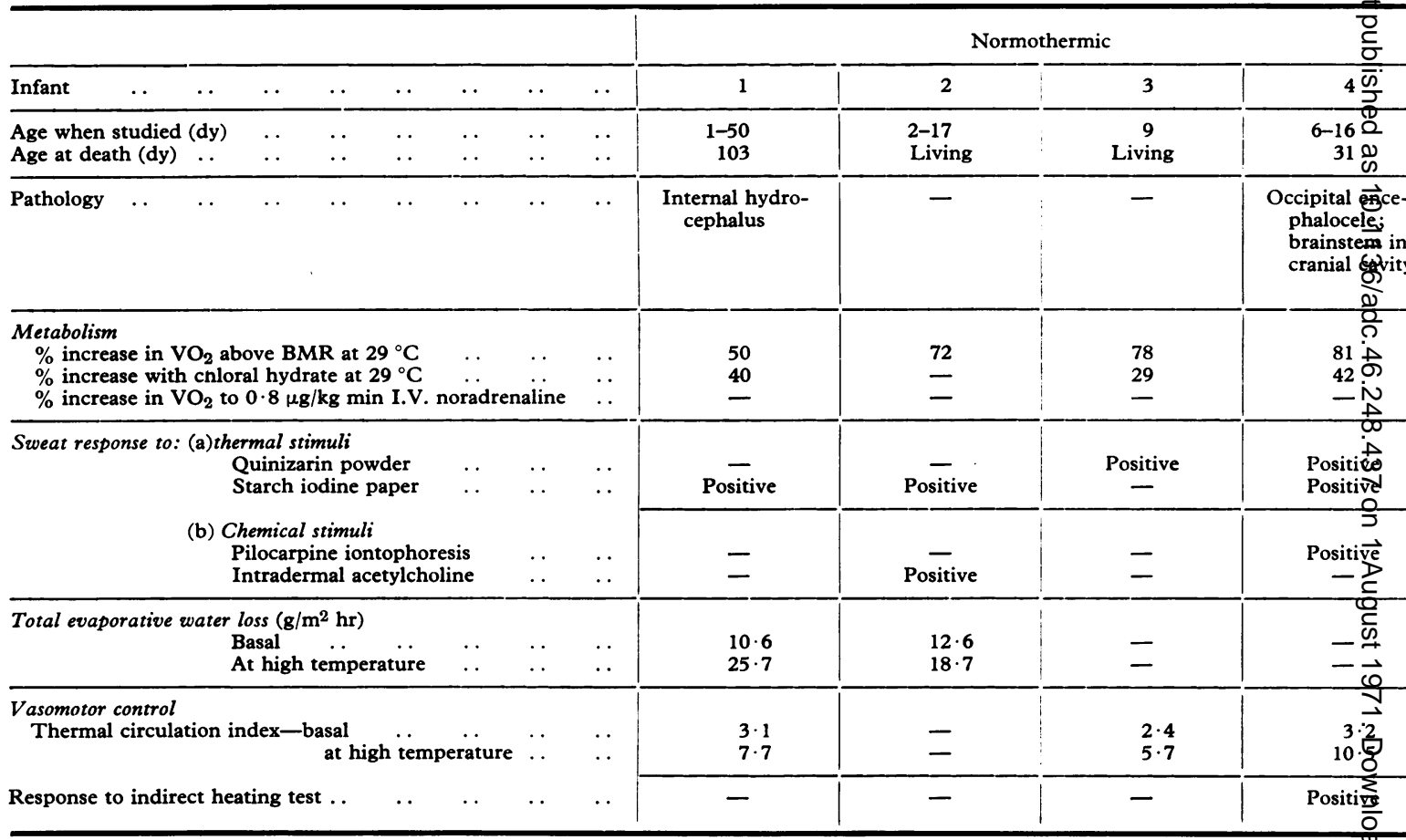

vasodilatation or increase in hand temperature could be detected when the trunk was warmed and body temperature rose to $38^{\circ} \mathrm{C}$. A very significant and sustained drop in heat flow through the hand was however observed in 2 infants during noradrenaline infusion in a warm environment.

Insensible water loss was measured in 5 of these infants and was normal in an environment of 33-34 ${ }^{\circ} \mathrm{C}$, but no increase in evaporative loss occurred in a warm environment $\left(\geqq 36^{\circ} \mathrm{C}\right)$ even when the rectal temperature reached $37 \cdot 8{ }^{\circ} \mathrm{C}$. None of these infants sweated anywhere on the body in an environment of $36^{\circ} \mathrm{C}$ and no sweat secretion could be elicitated by pilocarpine iontophoresis in 4 of these infants or by acetylcholine in a further 2 .

In infant 8 (occipital encephalocele), it was observed that the values of oxygen consumption were high in a neutral environment when the rectal temperature was within normal limits. This particular infant had frequent seizures so it was decided to sedate the infant with chloral hydrate $(50 \mathrm{mg} / \mathrm{kg}$ ) and to repeat the estimations. There was a significant decrease in oxygen consumption and the frequency of the seizures on sedation. On a further occasion the infant was given intravenous diazepam $(0 \cdot 1 \mathrm{mg} / \mathrm{kg})$ and again a decrease in oxygen consumption and frequency of seizure activity was observed. The oxygen consumption again increased when the drug was no longer active. Infant 5 was also noted to have a number of small seizures and this may be the explanation of the variable values of oxygen consumption obtained (Fig. 1). Table II summarizes the findings in the two groups of babies.

Pathology. All 7 infants died and necropsies were performed.

Cases 5,7 , and 8: Extensive, generally asymmetrical, herniation of cerebral hemispheres into encephalocele. Hypothalamus distorted, often asymmetrically, but main landmarks identifiable at least in one hemisphere. Gross malformation of hindbrain with vestigial cerebellum and grossly deformed brainstem displaced into hernial sac. Few identifiable fibre tracts and brainstem nuclei. Constriction of structures lying in hernial neck with secondary vascular lesions or scarring.

Case 6: Extensive herniation of cerebral hemisspheres. Hypothalamus somewhat distorted, but all main landmarks identifiable with exception of 


\begin{tabular}{|c|c|c|c|c|c|c|}
\hline \multicolumn{7}{|c|}{ Poikilothermic } \\
\hline 5 & 6 & 7 & 8 & 9 & 10 & 11 \\
\hline $\begin{array}{r}1-65 \\
128\end{array}$ & $\begin{array}{r}0-3 \\
6\end{array}$ & $\begin{array}{r}13-20 \\
58\end{array}$ & $\begin{array}{r}2-6 \\
12\end{array}$ & $\begin{array}{r}1-2 \\
67\end{array}$ & $\begin{array}{r}0-3 \\
3\end{array}$ & $\begin{array}{r}0-2 \\
2\end{array}$ \\
\hline \multicolumn{4}{|c|}{$\begin{array}{l}\text { Occipital encephalocele } \\
\text { hind-brain malformations; } \\
\text { brain-stem in hernial sac }\end{array}$} & $\begin{array}{l}\text { Hydrocephalus } \\
\text { Arnold-Chiari } \\
\text { malformation; } \\
\text { cervical } \\
\text { myelocele }\end{array}$ & \multicolumn{2}{|c|}{ Anencephaly } \\
\hline $\begin{array}{r}9 \\
-5 \\
2\end{array}$ & $\frac{-4}{51}$ & $\frac{-6}{26}$ & $\begin{array}{r}2 \\
-23 \\
-\end{array}$ & $\frac{19}{-}$ & $\frac{2}{=}$ & $\underline{-3}$ \\
\hline Negative & $\begin{array}{l}\text { Negative } \\
\text { Negative }\end{array}$ & $\begin{array}{l}\text { Negative } \\
\text { Negative }\end{array}$ & Negative & Negative & Negative & $\begin{array}{l}\text { Negative } \\
\text { Negative }\end{array}$ \\
\hline Negative & Negative & $\begin{array}{l}\text { Negative } \\
\text { Negative }\end{array}$ & Negative & Negative & $=$ & Negative \\
\hline $\begin{array}{r}10.9 \\
11.3 \\
\end{array}$ & $\begin{array}{l}10.5 \\
11.0 \\
\end{array}$ & $\begin{array}{r}8.3 \\
10.5 \\
\end{array}$ & $\begin{array}{r}9.9 \\
11.7 \\
\end{array}$ & 9.9 & $=$ & $\begin{array}{l}9 \cdot 3 \\
9 \cdot 3\end{array}$ \\
\hline $\begin{array}{l}2 \cdot 3 \\
2 \cdot 5\end{array}$ & $\begin{array}{l}2 \cdot 2 \\
2 \cdot 0\end{array}$ & $\begin{array}{l}3.6 \\
3.9\end{array}$ & $=$ & $\bar{z}$ & $\begin{array}{l}2 \cdot 1 \\
2 \cdot 1\end{array}$ & $=$ \\
\hline Negative & Negative & Negative & - & - & - & Negative \\
\hline
\end{tabular}

mamillary bodies and their connexions. Brainstem wholly within cranial cavity, but grossly malformed, particularly at upper end, with few identifiable landmarks. Total absence of cerebellum.

Case 9: Gross hydrocephalus. Structure of diencephalon partially obscured by large islands of ectopic grey matter. Arnold-Chiari malformation of hind-brain. Large myelocele in lower cervical and upper thoracic region with interruption of long tracts.

Cases 10 and 11: Anencephaly; no organized structures above level of brainstem.

\section{Discussion}

The evidence assembled is consistent with the view that lack of temperature control was associated with developmental defects in the region of the hypothalamus or its connexions. The three infants who presented with raised intracranial pressure, cortical thinning, and dilated ventricles in the neonatal period had normal thermoregulatory function in contrast to the older child reported by Gubbay (1967). The lack of temperature control in the two cases of anencephaly confirms and amplifies the findings of Cross et al. (1966). It seems probable that similar findings would be encountered in some cases of hydranencephaly (Watson, 1944). The prognosis in cases of cranium bifidum varies greatly (Barrow and Simpson, 1966), and it should perhaps be stressed that temperature control usually seems to be normal in infants without microcephaly or extensive herniation of brain tissue even when the sac is large.

Temperature control can be disturbed following intracranial haemorrhage at birth (Mestyán, 1962), but significant haemorrhage was found only in one infant with an encephalocele at necropsy, and this was thought to have been a sudden terminal event. To show conclusively that the lack of temperature control was due to the central nervous defects found at necropsy it would be necessary to show that the afferent and efferent arcs of the various reflexes were intact. It was unfortunately not possible to show that sensory function was unequivocally normal but it was possible to show that most of the effector organs were functional.

Noradrenaline infusion showed that two of the babies with a large occipital encephalocele were capable of increasing their heat production as in 
normal babies (Karlberg, Moore, and Oliver, 1962, 1965) while the changes in blood chemistry are consistent with the view that this is due to increased metabolism in brown adipose tissue (Dawkins and Scopes, 1965; Persson and Gentz, 1966). The presumed increase in blood pressure during the same infusion and the fall in heat flow through the skin similarly indicate that the blood vessels were able to constrict on direct stimulation. The absence of any increase in heat production in infant 5 can probably be attributed to the breakdown of the infused noradrenaline during its passage from the portal system through the liver.

Hypothermia is a common accompanying sign in the infants who failed to increase their heat production on cold exposure. In infant 8 , a high minimal oxygen consumption was obtained; this high value may have been due to the presence of seizure activity, as both the $\dot{\mathrm{VO}}{ }_{2}$ and seizure activity were substantially lowered following sedation. These infants are able to achieve high levels of basal heat production and consequently are less vulnerable to hypothermia. This may explain why the presence of hypothermia has not been more frequently recorded in these infants.

Sweat function. The absence of any thermal sweat response in five of the infants was in keeping with the lack of other evidence of temperature control. What was quite unexpected was the lack of any response to direct chemical stimulation, as Foster, Hey, and Katz (1969) showed that all normal babies sweat at birth, both to thermal and to chemical stimulation, unless born at least two or three weeks before term. The response to pilocarpine is lost after damage to the post-ganglionic sympathetic nerves, but is normally retained after preganglionic sympathectomy (Hyndman and Wolkin, 1941). The integrity of the postganglionic nerves was unfortunately not tested, but there was no reason to suppose that these nerves were abnormal. Neither was it thought safe to test the response of the glands to direct local heat (Randall, 1947). The sweat glands appeared normal on routine histological examination after death, but few histological changes normally occur in denervated non-functioning glands (Silver, Montagna, and Versaci, 1964), apart from a reduction in cholinesterase.

Investigation of a larger group of babies with defects of central nervous system at birth has since confirmed these findings (Foster, Hey, and O'Connell, 1971) and also shown that, in at least a proportion of infants lacking any sweat response to thermal or chemical stimuli, an axon reflex can be elicited in the postganglionic sympathetic 을 nerve with acetylcholine (Coon and Rothman, $\overrightarrow{\vec{F}}$ 1940) or faradic stimulation (Lewis and Marvin, $\stackrel{\vec{P}}{+}$ 1927). It seems therefore that full functional maturation of sweat glands at birth probably $\frac{\bar{\sigma}}{\bar{D}}$ depends on an intact central innervation in utero.

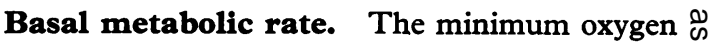
consumption of the normal human infant asleep in $\overrightarrow{0}$ a neutral thermal environment rises significantly during the first few days after birth. The initial rise $\vec{\omega}$ is rapid in the term infant, but occurs more gradually in babies weighing under $2 \mathrm{~kg}$. The sharp rise in the first two days of life has been noted in a number of species (Mott, 1963) and its cause has is been the subject of speculation. Alexander (1961) $\stackrel{+}{\infty}$ considered that it might be related in part at least to the onset of feeding. Cross et al. (1966) noting $\omega_{V}$ that the minimum oxygen consumption of the $\frac{\text { 의 }}{2}$ anencephalic infant they studied was rather less than that normally found in term infants of the same age and weight, speculated that some of the rise could be due to an increase in central nervous $\stackrel{\infty}{\stackrel{5}{+}}$ activity in normal infants after birth, as brain $\vec{\varphi}$ tissue is known to have a high oxygen consumption. We have had the chance to study 2 infants with anencephaly and 5 infants with severe encephalocele and little normal cerebral cortex during first three days of life. These infants were not fed during this time though they were given a little water by mouth. Minimum oxygen consumption was nearly $\stackrel{\mathbb{Q}}{\square}$ $7 \mathrm{ml} / \mathrm{kg}$ min (which is within normal limits) in $4 \overrightarrow{\overrightarrow{0}}$ infants on the 3rd day of life, and in 2 infants there 3 was a significant rise in minimal oxygen consumption during first 48 hours after birth. It seems unlikely therefore that either feeding or cerebral function is decisive in influencing the large change in basal metabolism normally observed in the first 3 days of life.

We thank Drs. R. H. Dobbs and A. D. M. Jackson who asked us to investigate these patients, and are $\frac{}{3}$ deeply indebted to our nurse-technicians for conscien- $D$ tious help. Our thanks are also due to Dr. Gary Katz, o Dr. Peter Maurice, and Dr. Bridget O'Connell who helped with some observations.

\section{REFERENCES}

Alexander, G. (1961). Temperature regulation in the newborn $N$ lamb. Australian fournal of Agricultural Research, 12, 1152. $\sigma$ Barrow, N., and Simpson, D. A. (1966). Cranium bifidum. Investigation, prognosis and management. Australian Paedia- $Q$ tric Fournal, 2, 20.

Coon, J. M., and Rothman, S. (1940). The nature of the pilomotor $\mathbb{D}$ response to acetylcholine; some observations on the pharmacodynamics of the skin. Fournal of Pharmacology and Experi- $\square$ mental Therapeutics, 68, 301.

Cooper, K. E. (1965). Quantitative observations in disordered temperature regulation. In The Scientific Basis of Medicine, Annual Reviews, 1965, 239. 


\section{Lack of Temperature Control in Infants with Abnormalities of Central Nervous System}

Cross, K. W., Gustavson, J., Hill, J. R., and Robinson, D. C. (1966). Thermoregulation in an anencephalic infant as inferred from its metabolic rate under hypothermic and normal conditions. Clinical Science, 31, 449.

Davison, C., and Friedman, E. D. (1937). Poikilothermia with hypothalamic lesions. Archives of Neurology and Psychiatry, 38, 1271.

Dawkins, M. J. R., and Scopes, J. W. (1965). Non-shivering thermogenesis and brown adipose tissue in the human newborn infant. Nature (London), 206, 201.

Foster, K. G., Hey, E. N., and Katz, G. (1969). The response of the sweat glands of the new-born baby to thermal stimuli and to intradermal acetylcholine. Fournal of Physiology, 203, 13.

Foster, K. G., Hey, E. N., and O'Connell, B. (1971). Sweat function in babies with defects of the central nervous system. Archives of Disease in Childhood, 46, 444.

Gibson, L. E., and Cooke, R. E. (1959). A test for concentration of electrolytes in sweat in cystic fibrosis of the pancreas utilising pilocarpine by iontophoresis. Pediatrics, 23, 545.

Gubbay, S. S. (1967). Derangement of temperature control in hydrocephalus. Developmental Medicine and Child Neurology, Suppl. 13, 125.

Guttmann, L. (1940). Topographic studies of disturbances of sweat secretion after complete lesions of peripheral nerves. fournal of Neurology and Psychiatry, 3, 197.

Hey, E. N. (1969). The relation between environmental temperature and oxygen consumption in the new-born baby. Fournal of Physiology, 200, 589.

Hey, E. N., and Katz, G. (1969). Evaporative water loss in the new-born baby. Fournal of Physiology, 200, 605.

Hey, E. N., and Katz, G. (1970). The range of thermal insulation in the tissues of the new-born baby. Fournal of Physiology, 207, 667.

Hill, J. R., and Rahimtulla, K. (1965). Heat balance and the metabolic rate of newborn babies in relation to environmental temperature; and the effect of age and weight on basal metabolic rate. Fournal of Physiology, 180, 239.

Hyndman, O. R., and Wolkin, J. (1941). The pilocarpine sweating test. I. A valid indicator in differentiation of preganglionic and postganglionic sympathectomy. Archives of Neurology and Psychiatry, 45, 992.

Karlberg, P., Moore, R. E., and Oliver, T. K., Jr. (1962). The thermogenic response of the newborn infant to noradrenaline. Acta Paediatrica, 51, 284.

Karlberg, P., Moore, R. E., and Oliver, T. K., Jr. (1965). Thermogenic and cardiovascular responses of the newborn baby to noradrenaline. Acta Paediatrica, 54, 225.

Lewis, T., and Marvin, H. M. (1927). Observations upon a pilomotor reaction in response to faradism. Fournal of Physio$\log y, 64,87$.

Lewis, T., and Pickering, G. W. (1931). Vasodilation in the limbs in response to warming the body; with evidence for sympathetic vasodilator nerves in man. Heart, 16, 33.

Mestyán, J. (1962). Neonatal cold injury. Lancet, 1, 690.

Mott, J. C. (1963). Oxygen consumption in the newborn. Federation Proceedings, 22, 814.

Persson, B., and Gentz, J. (1966). The pattern of blood lipids, glycerol and ketone bodies during the neonatal period, infancy and childhood. Acta Paediatrica, 55, 353.

Randall, W. C. (1947). Local sweat gland activity due to direct effects of radiant heat. American fournal of Physiology, 150, 365.

Silver, A. Montagna, W, and Versaci, A. (1964). The effect of denervation of sweat glands and Meissner corpuscles of human hands. Fournal of Investigative Dermatology, 42, 307.

Watson, E. H. (1944). Hydranencephaly. Report of two cases which combine features of hydrocephalus and anencephaly. American fournal of Diseases of Children, 67, 282.

Young, I. M. (1962). Vasomotor tone in the skin blood vessels of the newborn infant. Clinical Science, 22, 325.

Address for reprints and correspondence: Professor K. W. Cross, Department of Physiology, London Hospital Medical College, Turner Street, London E1 2AD. 